Review Article

\title{
Peripheral Nerve Dysfunction after Spinal Cord Injury
}

Mary P Galea ${ }^{1,2,}{ }^{*}$, Natasha van $\mathrm{Zyl}^{3}$, Aurora Messina $^{1}$

1. Department of Medicine (Royal Melbourne Hospital), The University of Melbourne, Parkville, VIC 3052, Australia; E-Mails: m.galea@unimelb.edu.au; messinaa@unimelb.edu.au

2. Victorian Spinal Cord Service, Austin Health, Heidelberg, VIC 3084, Australia

3. Department of Plastic and Reconstructive Surgery, Austin Health, Heidelberg, VIC 3084, Australia; E-Mail: natasha@natashavanzyl.com.au

* Correspondence: Mary P Galea; E-Mail: m.galea@unimelb.edu.au

Academic Editor: Ping K Yip

Special Issue: Neuroprotection, Neuroregeneration and Neuroplasticity

OBM Neurobiology

2020, volume 4, issue 4

doi:10.21926/obm.neurobiol.2004075
Received: October 02, 2020

Accepted: December 24, 2020

Published: December 29, 2020

\begin{abstract}
Spinal cord injury $(\mathrm{SCl})$ leads to an immediate loss of sensory and motor function below the level of injury mostly affecting people in the prime of life. In addition to the primary injury there is accumulating neurophysiological and histological evidence of dysfunction in the peripheral nerves, not related to direct damage from the primary injury, which exacerbates muscle wasting, and contributes to further functional loss and poor recovery. Among the potential contributing factors are systemic inflammation, and motor neuron and myelin abnormalities that result from a lack of neural traffic. The reversibility of these factors, and prevention strategies and possible therapies that may be of benefit to the peripheral nerves in spinal cord injury require further investigation. Preventing or reversing peripheral nerve dysfunction after $\mathrm{SCl}$ is essential to maintain this critical component of the nervous system in readiness for the application of other emerging interventions focused on spinal cord repair.
\end{abstract}

\section{Keywords}

Peripheral nerve dysfunction; spinal cord injury; myelin

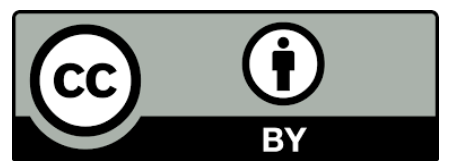

(C) 2020 by the author. This is an open access article distributed under the conditions of the Creative Commons by Attribution License, which permits unrestricted use, distribution, and reproduction in any medium or format, provided the original work is correctly cited. 


\section{Introduction}

Spinal cord injury (SCl) leads to an abrupt severe lifelong impairment of sensorimotor function. The annual crude incidence rates of traumatic $\mathrm{SCl}$ varies from 12.1 per million to 57.8 per million, with leading causes being motor vehicle accidents, falls, violence and sports activities [1]. In the USA, the estimated lifetime costs associated with tetraplegia are between US\$3.5 million to $\$ 4.7$ million and for paraplegia around US\$2 million [2].

$\mathrm{SCl}$ results in loss of sensory and motor function below the level of injury, leading to a profound muscular atrophy and, in lesions above T4, autonomic dysfunction. It is understood that these sequelae result from the loss of descending electrical activity from the brain. However, unless there is direct damage to the motor neurons within the injury zone and/or the nerve roots (e.g. cauda equina injury), it has been assumed that the spinal circuitry and peripheral nervous system below the level of injury remain largely intact, both morphologically and electrophysiologically. Indeed numerous studies in both animals [3] and humans [4] have demonstrated that the spinal cord retains the ability to produce oscillating patterns of muscle activity such as those required for gait. Sensory information about lower extremity loading provides important cues that modulate the patterns of muscle activity [4]. The presence of intact motor neurons provides the basis for functional electrical stimulation of the paralysed muscles below the level of injury [5]. Thus, the peripheral nervous system remains a critical component in the modulation of spinal cord activity below the level of injury.

\section{Peripheral Nerve Dysfunction Related to Direct Spinal Cord Trauma}

Traumatic injury to the spinal cord leads to a primary injury as a result of impact, compression, or laceration, which directly damage neurons within the injury zone as well as ascending and descending tracts. A secondary injury cascade involving vascular dysfunction, oedema, ischemia, excitotoxicity, electrolyte shifts, free radical production, inflammation, and cell death leads to further tissue destruction. Since grey matter destruction often extends rostral and caudal to the primary injury site, motor neurons or nerve roots over a number of segments adjacent and caudal to the primary injury site may be affected, leading to lower motor neuron injury (LMN) which may be partial $[6,7]$. Below the lesion, this may be masked by the upper motor neuron injury [8], and the extent of LMN lesions may be under-recognised [9].

A LMN injury may not be apparent soon after injury, but compound motor action potentials disappear over a period of 1 month [10]. Wallerian degeneration, involving axonal degeneration and fragmentation of the myelin sheath, commences between 24 and 48 hours after injury, depending on axon size [11], and occurs over a period of 7-10 days. Collateral sprouting of spared motor neuron terminal branches in partially damaged nerves results in innervation of denervated muscle fibres and an increase in motor unit size (i.e., the number of muscle fibres innervated by a single motor neuron) $[12,13]$. This process may restore muscle strength, and may underlie the functional recovery observed in the early stage after injury [7]. 


\section{Compression or Traction Injuries of Peripheral Nerves}

A number of studies have reported frequent sensory and motor nerve dysfunction in people with clinically complete $\mathrm{SCl}$, possibly resulting from mechanical compression and/or traction. Indeed, carpal tunnel syndrome and median nerve neuropathy are highly prevalent in people with paraplegia who are manual wheelchair users [14-18]. In addition to median nerve neuropathy, Nogajski et al. [19] reported focal neuropathies affecting the ulnar nerve, and lower limb nerves (sciatic and common peroneal nerves) that were more common in patients with tetraplegia and may be explained by compression due to positioning.

\section{Generalised Peripheral Nerve Dysfunction after Spinal Cord Injury}

Apart from compression-related injuries, more generalised evidence of peripheral nerve dysfunction after $\mathrm{SCl}$ has been reported [19-25]. To date, these investigations have involved electrophysiological techniques, mainly motor and sensory nerve conduction studies combined with electromyography. Such techniques are sensitive to the integrity of the myelin sheath and studies using them have reported slowed motor conduction, reduced amplitude of compound action potentials, fibrillations and aberrant neuromuscular junction transmission in patients with $\mathrm{SCl}$ [23, 27]. Using threshold tracking techniques [28] (i.e. stimulus-response curves, strength-duration properties, threshold electrotonus, a current-threshold relationship and the recovery cycle), Lin et al [27] reported a high stimulation threshold of motor axons and reduced amplitudes of compound action potentials in patients with $\mathrm{SCl}$, consistent with axonal degeneration. While such changes in the upper limbs of people with tetraplegia could reflect irreversible axonal degeneration as a result of direct damage of motor neurons from primary and secondary injury processes at the time of injury, their presence in the lower limbs, far from the injury site, have been reported to reflect transsynaptic degeneration $[21,28]$. However, the reported electrophysiological changes are also consistent with aberrant myelination and demyelination, and enlargement, loss and distortion of the nodes of Ranvier, which may be reversible. These changes occur do not necessarily involve axonal deterioration nor Wallerian degeneration. A further study of changes in nerve excitability during inpatient admission in patients with acute $\mathrm{SCl}$ [29] found that although results from nerve conduction studies remained within normal limits, there were significant changes in excitability, more pronounced in the lower limb. The marked reduction of electrical 'traffic' along the nerve exacerbates muscle wasting, and contributes to further loss of function and poor recovery [10].

\section{Histological Abnormalities in Human Peripheral Nerves}

Direct assessment of peripheral nerve morphology in human $\mathrm{SCl}$ has not been possible to date. However, the recent application of nerve transfer surgery [30-34] to restore volitional control to arm and hand muscles in people with cervical $\mathrm{SCl}$ presents a novel, unique and rare opportunity to sample peripheral nerves after $\mathrm{SCl}$ without morbidity. Nerve transfer surgery involves the transfer of nerve branches (originating above the injury zone) from an expendable muscle retaining volitional control (donor nerve) to an intact but non-functioning recipient nerve below the level of injury, with the aim of restoring volitional control of important functions. This type of surgery reanimates muscle groups without altering their biomechanics [35]. Common transfers include the teres minor (TM) to triceps nerve for elbow extension, the supinator to posterior interosseous nerve 
(PIN) for finger and thumb extension, the extensor carpi radialis brevis (ECRB) nerve or the brachialis nerve branch to the anterior interosseous nerve (AIN) for extrinsic thumb flexion and reanimation of flexor digitorum profundus to the index and middle finger.

Fox et al [32] described decreased fibre density in two of seven anterior interosseous nerves sampled at the time of nerve transfer surgery. In our recent, more extensive morphological study [36] specimens of donor and recipient nerves were collected from three participants with cervical $\mathrm{SCl}$ who were referred for surgical reanimation of hand function. Donor nerves included teres minor, posterior axillary, brachialis, extensor carpi radialis brevis and supinator. Recipient nerves included triceps, posterior interosseus (PIN) and anterior interosseus nerves (AIN). A qualitative assessment showed that $80 \%$ of the nerves showed abnormalities, with the most common being myelin thickening and folding, demyelination, inflammation and a reduction of large myelinated axon density. Others were a thickened perineurium, oedematous endoneurium and Renaut bodies. Significantly, very thinly myelinated axons and groups of unmyelinated axons were observed. These probably are indicative of regenerative efforts rather than thinly myelinated A $\delta$ fibres, since the nerve fascicles involved in nerve transfer surgery are identified intra-operatively as motor fascicles.

Abnormalities were observed in both donor and recipient nerves and they differed in appearance and aetiology. Figures 1 and 2 show axonal and myelin abnormalities in donor (nerves to supinator and teres minor) and recipient (anterior interosseus and posterior interosseus nerves and nerve to triceps) nerves. Donor nerves had predominantly reduced axon density, Renaut bodies and regenerating axons, whereas the recipient nerves had more severe myelin abnormalities. The pathophysiological mechanisms underlying such changes are not understood and are likely to be multifactorial. Some of these are discussed in detail below.

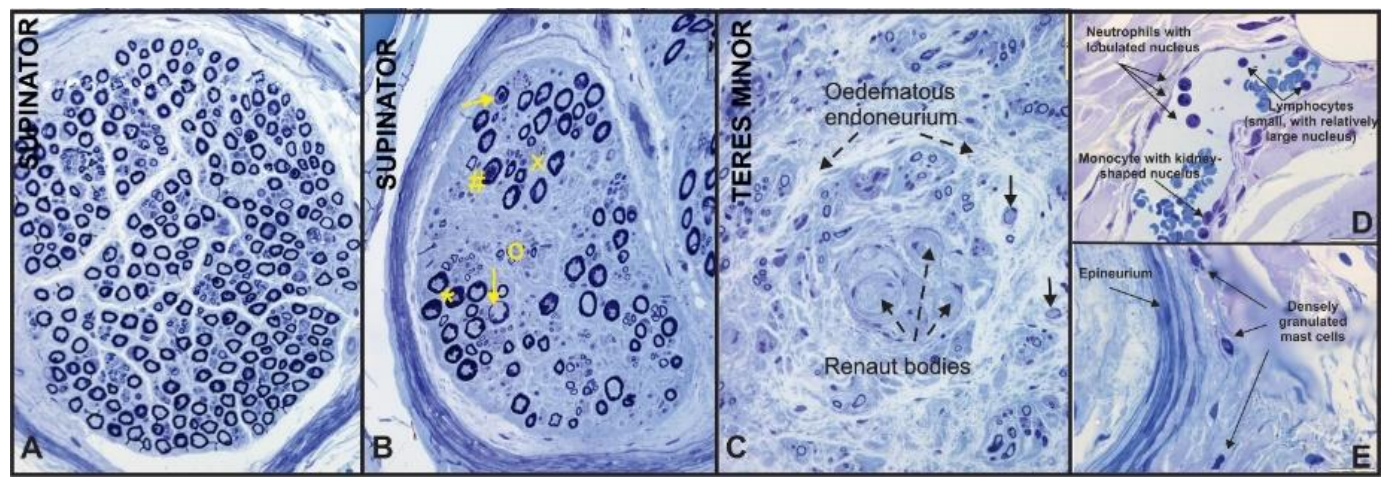

Figure 1 Light micrographs of methylene blue stained cross-sections from donor supinator and teres minor nerves in participants with $\mathrm{SCl}$. Nerve fascicles in A have relatively normal axon density and myelin (M). Nerve fascicles in B have reduced axon density and aberrant myelin, including thinning and demyelination (arrows), thickening $\left({ }^{*}\right)$ and folding (\#). Teres minor nerve in $C$ has a sparsely populated endoneurium with small thinly myelinated/demyelinated axons (solid arrows) and an oedematous endoneurium and prominent Renaut bodies (dotted arrows). $\operatorname{Bar}(A-C)=50 \mu \mathrm{m}$. D shows an epineural blood vessel infiltrated with mononuclear blood cells, neutrophils and lymphocytes. $E$ shows epineural connective tissue infiltrated by mast cells. Bar $(D, E)=$ $20 \mu \mathrm{m}$. Micrographs: A \& B are from two participants with $\mathrm{SCl}$ at $\mathrm{C} 5,11$ months postinjury; C from a participant with $\mathrm{SCl}$ at C5, 10 months post-injury; D \& E from participants with $\mathrm{SCl}$ level C4 12 months and level C5 at 7.5 months respectively. 


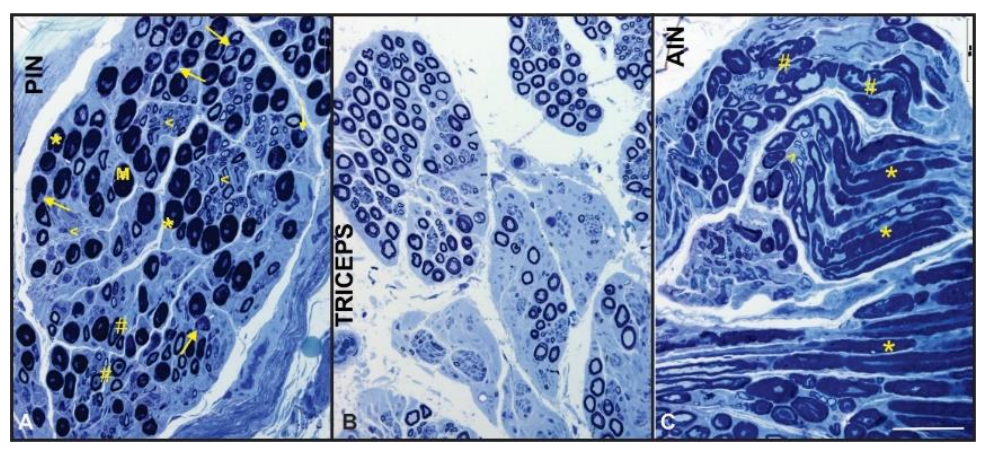

Figure 2 Light micrographs of methylene blue stained cross-sections from recipient nerves in participants with $\mathrm{SCl}$. Nerve fascicles in A show reduced axon density, myelin (M) thinning and demyelination (arrows), thickening $\left({ }^{*}\right)$, small thinly myelinated axons $(<)$ and infolding (\#). B shows reduced axon density. $C$ is a partial longitudinal section shows extensive myelin thickening $\left({ }^{*}\right)$ and infolding $(\#)$ and small thinly myelinated axons (<). PIN=posterior interosseous nerve, $\mathrm{AIN}=$ anterior interosseous nerve. $\mathrm{Bar}=$ $50 \mu \mathrm{m}$. Micrographs: A, B, C are from a participant with $\mathrm{SCl}$ at $\mathrm{C} 5,11$ months post-injury.

\section{Effect of $\mathrm{SCl}$ on Motor Neuron Function}

The loss of signals from the brain after $\mathrm{SCl}$ result in anatomical and functional changes in the neuronal circuitry below the level of injury [37]. Importantly, loss of descending input to the motor neurons below the level of injury has a profound effect on their integrity and function [28]. The number of motor neurons in the sub-lesional spinal cord appear to remain unchanged after injury in humans and in experimental animals [38-41]. However, a study using intraneural motor axon stimulation in humans showed that motor neuron excitability may depend on how close the motor neurons are to the site of injury. For example, thenar motor neurons became more excitable after $\mathrm{SCl}$ at $\mathrm{C} 4$, and less excitable after $\mathrm{SCl}$ at $\mathrm{C} 5$ or $\mathrm{C} 6$ compared with motor neurons in able-bodied people [42]. Studies in experimental animals show a number of other changes. There is a reduction in the dendritic tree of motor neurons [43]. SCl leads directly to a loss of excitatory drive to the motor neurons, mediated by descending inputs to segmental interneurons, which are also a major source of synaptic inputs onto the motor neuron [44]. Such a loss of synaptic input may lead to a de-afferentation-induced remodelling of the dendritic architecture [45, 46]. Motor neuron excitability is reduced immediately after $\mathrm{SCl}[47,48]$, however in the chronic phase, motor units exhibit long-lasting discharges sustained by plateau potentials which contribute to exaggerated reflex activity and spasticity $[49,50]$.

Apart from loss of descending excitatory drive, there may be direct damage to motor neurons within the $\mathrm{SCl}$ zone which would lead to a lower motor neuron injury and/or reduced axon density in the peripheral nerve. It is important to note that the donor and recipient nerves used in the reanimation of the upper limb using nerve transfer surgery arise from motor neuron pools adjacent to the $\mathrm{SCl}$ which may be directly affected by the injury. However, neurophysiological evidence of high stimulation threshold of motor axons and reduced amplitudes of compound action potentials in lower limb peripheral nerves in patients with $\mathrm{SCl}$ [27] suggest that reduced axon density is a systemic phenomenon. Animal studies have shown that lack of muscle activity also affects motor neuron properties [51] which are dependent on trophic factors associated with muscle activity, that are retrogradely transported along motor axons [52]. Compared with simple limb immobilisation, 
$\mathrm{SCl}$ results in an increased proportion of intermediate fast twitch motor units at the expense of fatigue-resistant motor units [53].

Our observations of a reduction in the number of large myelinated axons is consistent with the electrophysiological changes previously reported, including a reduction or loss of compound action potentials [19-25, 27-29]. The presence of thinly myelinated or unmyelinated axons may be related to regenerative efforts associated with the response to the original LMN injury. If so, this highlights regeneration over a prolonged period, as the participants were more than 10 months post-injury (Figures 1, 2, 3).

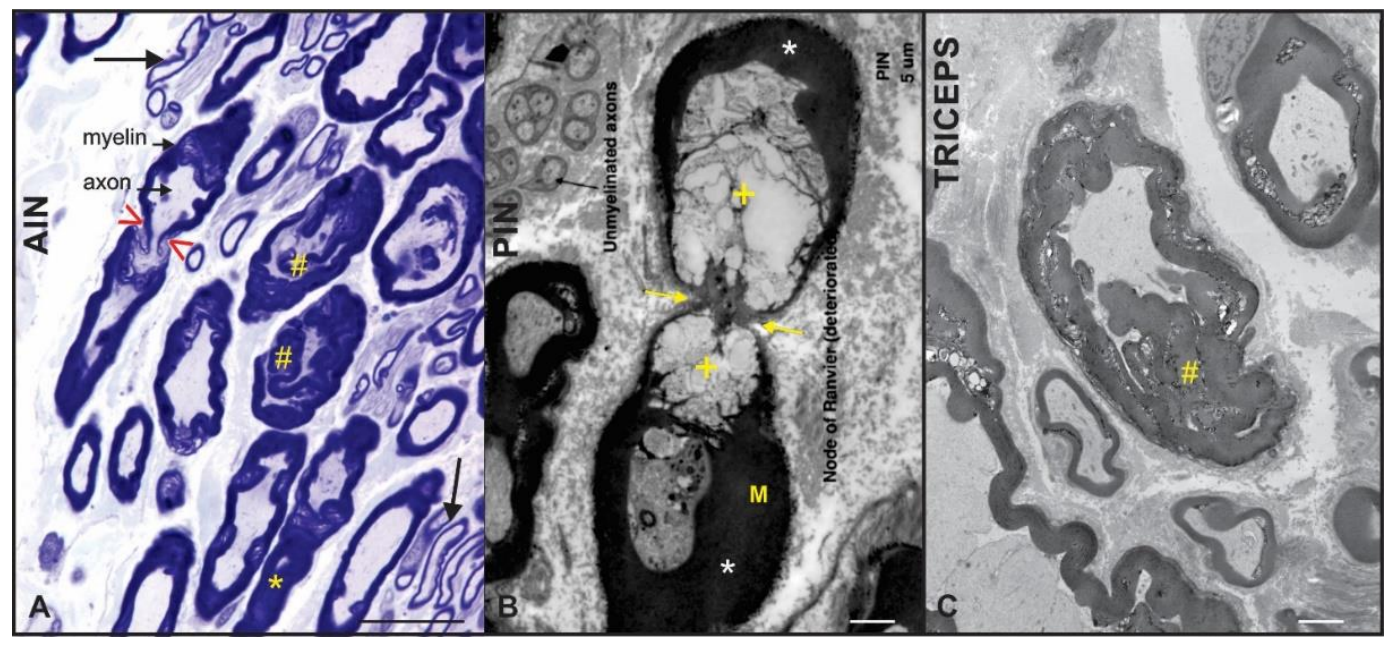

Figure $3 \mathrm{~A}$. Light micrograph of a toluidine blue-stained tangential section from the recipient anterior interosseous nerve (AIN). Note the pale stained axons, and darkly stained myelin showing abnormal thickening $(*)$ and infolding (\#). An abnormal node of Ranvier has overlapping myelinated regions and internalized Schwann cell loops (red <). Populations of relatively normal small thinly myelinated and unmyelinated axons (arrows) are also present. Bar $=20 \mu \mathrm{m}$. B. Electron micrograph of a node of Ranvier (yellow arrows) in longitudinal section from the recipient posterior interosseous nerve (PIN) from a participant with $\mathrm{SCl}$. Residual myelin is thickened (M). Schwann cell cytoplasm is absent from the nodal region and the axoplasm is deteriorated and cystic. Note unmyelinated axons (black arrow). Bar $=5 \mu \mathrm{m}$. C. Electron micrograph of recipient nerve (TRICEPS). Note infolded residual myelin (\#) with multiple regions of split lamellae, encroaching on the axon space but also detached from axon membrane. Bar $=5 \mu \mathrm{m}$. Micrographs: A from a participant with $\mathrm{SCl}$ at $\mathrm{C} 4,12$ months post-injury; $\mathrm{B} \& \mathrm{C}$ from a participant with $\mathrm{SCl}$ at $\mathrm{C} 5,11$ months post-injury.

Renaut bodies, observed only in the nerve to teres minor and the posterior axillary nerve in our study, are composed of spidery fibroblasts and perineurial cells, have been reported in more than $50 \%$ of nerves at risk of sub-clinical entrapment that are mainly located at sites of nerve compression $[54,55]$. The axillary nerve passes through the quadrilateral space accompanied by the posterior circumflex humeral artery and may be subject to compression. A neurovascular compression syndrome, the quadrilateral space syndrome, is an uncommon condition presenting as a complaint of shoulder pain combined with shoulder weakness [56]. It is difficult to diagnose, and weakness due to compression of this nerve may be masked in a person with tetraplegia. 
However, the axillary nerve is potentially another nerve in the upper limb that may be at risk of compression after $\mathrm{SCl}$ in addition to those already reported.

Studies in experimental animals have shown that the neuromuscular junction is selectively vulnerable to inactivity between and within muscles $[57,58]$. Skeletal muscles can be subdivided into two separate categories, Fast Synapsing and Delayed Synapsing, on the basis of distinct focal clustering of acetylcholine (AChR) receptors, the alignment of the presynaptic nerve with focal AChR clusters, and the alignment of Schwann cells with the presynaptic nerve terminal [59]. These two muscle types respond differentially to $\mathrm{SCl}$, with animal studies showing destabilised synapses in Fast Synapsing hindlimb flexor muscles (extensor digitorum longus and tibialis anterior), but not in Delayed Synapsing extensors (medial gastrocnemius and soleus) [60].

\section{Inflammation}

Human post-mortem studies of cases of $\mathrm{SCl}$ have shown that local ischemia predominantly affects the spinal grey matter due to damage of the anterior sulcal arteries and disruption of the microvasculature within the spinal cord at the time of injury [61]. Restoration of blood flow, while essential to salvaging of ischemic tissue, paradoxically causes further damage through release of reactive oxygen species [62], as well as inflammatory cytokines, such as TNF- $\alpha$, interleukins and interferons. Increased levels of inflammatory or metabolic products may directly affect channel function in the peripheral axons [63]. Immune factors such as anti-ganglioside GM1 antibodies have been shown to promote formation of antibody-complement complexes that could block sodium channels to disrupt the node of Ranvier [64]. People with SCl have chronic systemic inflammation and immune suppression [65] and this, in conjunction with existing neurological deficits, may make them more susceptible to developing channelopathies.

However, the axonal dysfunction could result from local, rather than systemic processes. The inflammatory response noted by Messina et al [36] was based on the observation of epineural vessel and connective tissue localisation of mononuclear blood cells, neutrophils, lymphocytes (Figure 1D) and mast cells (Figure 1E). Inflammation of the peripheral nervous system in patients with SCI may either contribute to, or be a response to, the abnormalities observed.

Axonal degeneration of sensory and motor axons has been identified as a feature of critical illness polyneuropathy and myopathy, which are frequent complications in patients admitted to intensive care units $[66,67]$. Such patients have multiple serious risk factors such as acute respiratory distress syndrome, sepsis or systemic inflammatory response syndrome or multiple organ failure. Systemic inflammatory response syndrome is also associated with trauma, including $\mathrm{SCl}$. Among the features of critical illness polyneuropathy are reversible channelopathies, and microcirculatory abnormalities leading to endoneural oedema [67].

\section{Schwann Cells and Myelination}

There are four classes of Schwann cells: myelinating Schwann cells (MSCs), nonmyelinating Schwann cells (NMSCs), perisynaptic Schwann cells (PSCs) (also known as terminal Schwann cells), and satellite cells of peripheral ganglia. The best characterised are MSCs, each of which wraps around a single large diameter axon, creating the myelin sheath necessary for efficient propagation of the action potential. PSCs are located at the neuromuscular junctions, where they cover, but do not completely wrap around, the presynaptic terminal of motor axons [68]. There is intimate contact 
between Schwann cells and peripheral axons along their entire length. A single Schwann cell myelinates up to $1000 \mu \mathrm{m}$ long internodes (discrete myelinated axonal segments separated by the nodes of Ranvier) [69] (Figure 3), therefore a minimum of 100 Schwann cells are required for every $10 \mathrm{~cm}$ of axon length. The nodes of Ranvier regulate nervous system activity. Node length is tightly controlled but is sensitive to Schwann cell integrity and myelin changes. The nodal region has three domains, the node, marked by clustering of sodium channels, the paranode, localised using the adhesion molecule Caspr, and the juxtaparanode, marked by clustering of potassium channels. Disruption of organisation of the nodal region results in pathophysiological changes associated with demyelinating diseases [68]. Arancibia-Cárcamo et al. [70] showed that differences in the length of nodes can fine-tune the activity of the nervous system and that this could result in electrical signals moving at different speeds through different nerve cells. These findings raise the possibility that nerve cells may not only actively alter the length of their nodes in order to alter their signal speed, but that external influences, such as loss of descending input or electrical stimulation may also affect node length.

Schwann cell and myelin abnormalities in the peripheral nervous system (PNS) (Figure 3) probably contribute to the electrophysiological abnormalities recorded in peripheral nerves and target muscles. Such myelin abnormalities in peripheral nerves of people with $\mathrm{SCl}$ have not previously been reported. In $\mathrm{SCl}$ the abrupt cessation of action potentials disrupts the calcium mediated activity-dependent communication between axons and Schwann cells, and it has been suggested that this compromises myelin integrity [71]. Altered myelination has been reported in the peripheral nerves of animal models of SCl and Charcot-Marie-Tooth disorders [72, 73] and studies of experimental Charcot-Marie-Tooth disease may provide some insight into mechanisms underlying peripheral nerve dysfunction in $\mathrm{SCl}$. Detachment of the myelin sheath and axonal atrophy have been observed after $\mathrm{SCl}$ in rats and were associated with electrophysiological abnormalities [71]. Separation of the axon from the associated myelin sheath has also been observed in the nerves of people with Charcot-Marie-Tooth disease. At high resolution, the changes are localised to the paranodal region and involve compromised Schwann cell functions and impaired Schwann cell-myelin interactions [72]. In experimental Charcot-Marie-Tooth disease, myelin infolding, similar to that shown in Figure 3, was observed. This was linked to constricted axons, suggesting that the infolding myelin may physically block axonal transport. The myelin infolding was also associated with a widened nodal gap at the node of Ranvier and preceded the node of Ranvier abnormalities [73]. It has been proposed that the myelin infolding and nodal abnormalities are caused by defects in the maintenance of the myelin sheath and the Schwann cell-axon relationship, and may be the precursors of demyelination and axonal degeneration [73, 74]. Examination of the nodes of Ranvier in the peripheral nerves of people with $\mathrm{SCl}$ at both the light microscopy (Figure $3 \mathrm{~A}$ ) and high resolution electron microscopy (Figure 3B, 3C) levels shows deterioration.

In nerve transfers the decentralised recipient axon is severed and subsequently undergoes axonal degeneration. This initiates a process of Wallerian degeneration, necessitating myelin removal by Schwann cells and macrophages, in order to enable the formation of Schwann cell tubes (bands of Büngner) to guide and support donor axons [75]. It has been shown that the larger the diameter of the nerve fibre, the slower the rate of degeneration, and that the thickness of the myelin sheath appears to be the main factor determining the rate of degeneration [76]. Therefore, the presence of a markedly increased volume of myelin would likely increase the time required for removal, exacerbating and extending the associated inflammatory responses, thereby delaying and 
possibly compromising formation of Schwann cell tubes for regeneration after nerve transfer surgery. Interventions that could reverse the formation of excess myelin applied prior to surgery, such as electrical stimulation, may normalise the myelin and thereby accelerate regeneration postsurgery.

\section{Interventions to Improve the Health of Peripheral Nerves after SCI}

Maintenance of peripheral nervous system function during the early period after SCl may lead to better functional outcomes. A number of different interventions have been investigated in animal models.

\subsection{Activity-Based Training}

In a rat model of intensive care, attenuation of hindlimb muscle fibre atrophy with passive cycling was accompanied by reduced oxidative stress, decreased myosin losses and spared forcegenerating capacity of the exercised muscles [77]. Gene expression of brain-derived neurotrophic factor (BDNF) and glial cell line-derived neurotrophic factor (GDNF), growth factors which help regulate neuronal survival and synaptic strength, was upregulated in paralysed muscles of spinal cord-injured rats after only one session of passive cycling [78]. Similarly, BDNF, neurotrophin-3 and neurotrophin-4 were upregulated in the lumbar spinal cord enlargement within four weeks of passive cycling, implying potentially bi-directional signalling via a neuromuscular retro/anterograde transport pathway [79]. However, caution needs to be applied, as increasing neural activity through exercise may have detrimental effects during the acute phase of sprouting in damaged peripheral nerves. Exercise was shown to compromise sprouting in the context of extensive partial denervation of rat hindlimb muscles [80].

Other forms of activity-based training have been used in other contexts. For example full recovery of whisking (the sweeping movement of the vibrissae) was restored with regular gentle mechanical stimulation (both manual and environmental) of paralysed vibrissal muscles and whisker pads following facial nerve injury in the rat [81]. This study highlights the importance of afferent input which plays a major role in shaping and maintaining the morphology of the dendritic tree [82, 83].

\subsection{Electrical Stimulation}

Only one study has specifically investigated the application of an intensive short-term peripheral nerve stimulation program to reverse electrophysiological changes in patients with chronic $\mathrm{SCl}$ [84]. A portable neuromuscular electrical stimulator was used to stimulate contraction of target muscles ( $450 \mu$ s pulses delivered at $100 \mathrm{~Hz}$ with a $2 \mathrm{~s}$ on-off cycle) for 30 minutes daily for 6 weeks. Nerve excitability studies showed that the axonal dysfunction was ameliorated after this program, although the mechanisms underlying the change are not understood. Moreover, this stimulation was applied passively to patients. Functional electrical stimulation (FES) on the other hand, enables patients to do functional tasks, e.g. grasping and releasing objects, and therefore has the added benefit of neuromodulation within the spinal cord through task-specific practice [85].

In spinal cord-injured humans, functional electrical stimulation (FES)-assisted exercise, mainly cycling and rowing, has been included in rehabilitation programs for many years. FES is delivered by 
stimulating the peripheral nerves of the muscles in the appropriate sequence required for the functional task, and a number of different types of neuroprostheses have been developed that utilise FES for assisting standing, walking and grasping [86]. This is only possible if the muscles can be stimulated, i.e. no complete LMN injury. Because FES directly stimulates the peripheral nerves, it provides a way of increasing neural traffic along the nerves through assisting with functional tasks. Most of the research to date has focused on reversing muscle atrophy, changes in muscle fibre type, and improvements in cardiorespiratory and metabolic health [87]. Increases in muscle strength have also been reported $[86,88]$, as well as a reduction in the levels of inflammatory markers, interleukin6 (IL-6), tumor necrosis factor-alpha (TNF-alpha), and C-reactive protein (CRP) [88]. However there have been no studies to date which have directly examined the effects of FES on peripheral nerves.

\section{Interventions to Improve Regeneration of Peripheral Nerves}

The context of nerve transfer surgery highlights the importance of peripheral nerve regeneration. The misdirection of regenerating axons after peripheral nerve transection has been considered to be a major factor associated with poor functional recovery $[89,90]$. A number of experimental interventions have been used to promote axonal regeneration after nerve repair, including a variety of neurotrophins, such as leukemia inhibitory factor (LIF) [91] or reducing inhibitory molecules in the environment, such as chondroitin sulfate proteoglycans [92]. However while these strategies were successful in promoting regeneration, they have also been shown to increase the amount of misdirection of regenerating axons and functionally inappropriate innervation [92]. Brief electrical stimulation applied just prior to transection also resulted in misdirection of regenerating axons [90].

Electrical stimulation upregulates neurotrophic factors such as BDNF and trkB in motor neurons after sciatic nerve injury in the rat [93] and has been applied at the time of repair of peripheral nerves to accelerate axonal regeneration and muscle reinnervation in animals and humans [94]. Two weeks of continuous low frequency $(20 \mathrm{~Hz})$ stimulation of an injured femoral nerve proximal to the injury site in the rat was shown to promote axonal regeneration, speeding the process from 8 weeks to 3 weeks [95]. However, even one hour of electrical stimulation at $20 \mathrm{~Hz}$ at the time of nerve repair was equally effective in promoting both motor and sensory axon regeneration [95]. Low intensity interval treadmill exercise has been shown to enhance axonal sprouting in rat common fibular nerve [96]. Electrical stimulation provided for one hour immediately after injury combined with two hours of daily treadmill running for four weeks led to increased axonal regeneration after sciatic nerve injury and repair in the rat [97]. However a high workload during the early period of reinnervation may be detrimental, so exercise of reinnervating muscle needs to be carefully titrated [98]. While there have been further studies investigating the timing and dosage of application of electrical stimulation in animals $[99,100]$, there have been a number of trials of this intervention in humans (reviewed in [101]). One hour of electrical stimulation at $20 \mathrm{~Hz}$, provided either intra-operatively or immediately post-operatively to patients who had surgical repair or decompression of peripheral nerves, led to improved function and showed proof of concept in translation of experimental findings to the clinic.

\section{Summary}

There are still many questions about the aetiology, ultrastructural, morphological and immunological characteristics, onset and progression of the abnormalities observed in the 
peripheral nerve after $\mathrm{SCl}$. The reversibility of the observed changes, and prevention strategies and possible therapies that may be of benefit to the peripheral nerves in spinal cord injury require further investigation. A better understanding of how peripheral nerve abnormalities in $\mathrm{SCl}$ may be reversed is essential in order to be able to develop/apply/predict therapies that maintain this critical component of the nervous system in readiness for the application of other emerging interventions focused on spinal cord repair.

\section{Ethics Statement}

Ethics approval (HREC/13/Austin/245, 18/12/2013) for taking peripheral nerve tissue samples during nerve transfer surgery was obtained from the Austin Health Human Research Ethics Committee. Research was conducted in accordance with the National Statement on Ethical Conduct in Human Research 2007 (Updated 2018), National Health and Medical Research Council of Australia. Informed consent was obtained from each participant.

\section{Acknowledgments}

We gratefully acknowledge the participants with spinal cord injury who agreed to the nerve biopsies being taken during nerve transfer surgery.

\section{Author Contributions}

MPG prepared the manuscript; NvZ performed the nerve transfer surgery and obtained nerve samples; AM performed all the histology; all authors reviewed and contributed to the final manuscript.

\section{Funding}

Grant from the Institute for Safety, Compensation and Recovery Research (Australia).

\section{Competing Interests}

The authors have declared that no competing interests exist.

\section{References}

1. Van den Berg ME, Castelloe JM, Mahillo-Fernandez I, de Pedro-Cuesta J. Incidence of spinal cord injury worldwide: A systematic review. Neuroepidemiol. 2010; 34: 184-192.

2. Spinal cord injury $(\mathrm{SCl})$ facts and figures at glance [Internet]. Birmingham: National Spinal Cord Injury Statistical Center; 2015.2 Available from: https://www.nscisc.uab.edu/Public/Facts\%202016.pdf.

3. Barbeau $\mathrm{H}$, Rossignol S. Recovery of locomotion after chronic spinalization in the adult cat. Brain Res. 1987; 412: 84-95.

4. Harkema SJ, Hurley SL, Patel UK, Requejo PS, Dobkin BH, Edgerton VR. Human lumbosacral spinal cord interprets loading during stepping. J Neurophysiol. 1997; 77: 797-811.

5. Ragnarsson KT. Functional electrical stimulation after spinal cord injury: Current use, therapeutic effects and future directions. Spinal Cord. 2008; 46: 255-274. 
6. Mandeville RM, Brown JM, Sheean GL. A neurophysiological approach to nerve transfer to restore upper limb function in cervical spinal cord injury. Neurosurg Focus. 2017; 43: E6.

7. Berman SA, Young RR, Sarkarati M, Shefner JM. Injury zone denervation in traumatic quadriplegia in humans. Muscle Nerve. 1996; 19: 701-706.

8. Bryden A, Kilgore KL, Nemunaitis GA. Advanced assessment of the upper limb in tetraplegia: A three-tiered approach to characterizing paralysis. Top Spinal Cord Inj Rehabil. 2018; 24: 206216.

9. Doherty JG, Burns AS, O'Ferrall DM, Ditunno JF. Prevalence of upper motor neuron vs lower motor neuron lesions in complete lower thoracic and lumbar spinal cord injuries. J Spinal Cord Med. 2002; 25: 289-292.

10. Van De Meent H, Hosman AJ, Hendriks J, Zwarts M, EM-SCl Study Group, Schubert M. Severe degeneration of peripheral motor axons after spinal cord injury: A European multicenter study in 345 patients. Neurorehabil Neural Repair. 2010; 24: 657-665.

11. Stoll G, Jander S, Myers RR. Degeneration and regeneration of the peripheral nervous system: From Augustus Waller's observations to neuroinflammation. J Periph Nerv Syst. 2003; 7: 13-27.

12. Bishop B. Neural plasticity part 3. Responses to lesions in the peripheral nervous system. Phys Ther. 1982; 62: 1275-1282.

13. Brown MC, Ironton R. Sprouting and regression of neuromuscular synapses in partially denervated mammalian muscles. J Physiol. 1978; 278: 325-348.

14. Blaik Z, McGarry J, Daura R. Peripheral neuropathy in spinal cord injured patients. Electromyogr Clin Neurophysiol. 1989; 29: 469-472.

15. Davidoff G, Werner R, Waring W. Compressive mononeuropathies of the upper extremity in chronic paraplegia. Paraplegia. 1991; 29; 17-24.

16. Nemchausky BA, Ubilluz RM. Upper extremity neuropathies in patients with spinal cord injuries. J Spinal Cord Med. 1995; 18: 95-97.

17. Yang J, Boninger ML, Leath JD, Fitzgerald SG, Dyson-Hudson TA, Chang MW. Carpal tunnel syndrome in manual wheelchair users with spinal cord injury. Am J Phys Med Rehabil. 2009; 88: 1007-1016.

18. Asheghan M, Hollisaz MT, Taheri T, Kazemi H, Aghda AK. The prevalence of carpal tunnel syndrome among long-term manual wheelchair users with spinal cord injury: A cross-sectional study. J Spinal Cord Med. 2016; 39: 265-271.

19. Nogajski JH, Engel S, Kiernan MC. Focal and generalized peripheral nerve dysfunction in spinal cord-injured patients. J Clin Neurophysiol. 2006; 23: 273-279.

20. Bursell JP, Little JW, Stiens SA. Electrodiagnosis in spinal cord injured persons with new weakness or sensory loss: Central and peripheral etiologies. Arch Phys Med Rehabil. 1999; 80: 904-909.

21. Kirshblum S, Lim S, Garstang S, Millis S. Electrodiagnostic changes of the lower limbs in subjects with chronic complete cervical spinal cord injury. Arch Phys Med Rehabil. 2001; 82: 604-607.

22. Riley DA, Burns AS, Carrion-Jones M, Dillingham TR. Electrophysiological dysfunction in the peripheral nervous system following spinal cord injury. PM R. 2011; 3: 419-425.

23. Kamradt $T$, Rasch $C$, Schuld $C$, Böttinger M, Můrle B, Hensel $C$, et al. Spinal cord injury: Association with axonal peripheral neuropathy in severely paralysed limbs. Eur J Neurol. 2013; 20: 843-848. 
24. Tankisi H, Pugdahl K, Rasmussen MM, Clemmensen D, Rawashdeh YF, Christensen $P$, et al. Peripheral nervous system involvement in chronic spinal cord injury. Muscle Nerve. 2015; 52: 1016-1022.

25. Moon CW, Jung IY, Cho KH. Electrophysiological changes in the peripheral nervous system after subacute spinal cord injury. Arch Phys Med Rehabil. 2020; 101: 994-1000.

26. Bostock $\mathrm{H}$, Cikurel K, Burke D. Threshold tracking techniques in the study of human peripheral nerve. Muscle Nerve. 1998; 21: 137-158.

27. Lin SY, Macefield VG, Elam M, Wallin BG, Engel S, Kiernan MC. Axonal changes in spinal cord injured patients distal to the site of injury. Brain. 2007; 130: 985-994.

28. Aisen ML, Brown W, Rubin M. Electrophysiologic changes in lumbar spinal cord after cervical spinal cord injury. Neurology. 1992; 42; 623-626.

29. Boland RA, Lin SY, Engel S, Kiernan MC. Adaptation of motor function after spinal cord injury: Novel insights into spinal shock. Brain. 2011; 134: 495-505.

30. Mackinnon SE, Yee A, Ray WZ. Nerve transfers for the restoration of hand function after spinal cord injury. J Neurosurg. 2012; 117: 176-185.

31. Van ZyI N, Hahn JB, Cooper CA, Weymouth MD, Flood SJ, Galea MP. Upper limb reinnervation in C6 tetraplegia using a triple nerve transfer: Case report. J Hand Surg. 2014; 39: 1779-1783.

32. Fox IK, Davidge KM, Novak CB, Hoben G, Kahn LC, Juknis N, et al. Use of peripheral nerve transfers in tetraplegia: Evaluation of feasibility and morbidity. Hand (N Y). 2015; 10: 60-67.

33. Van Zyl N, Hill B, Cooper C, Hahn J, Galea MP. Expanding traditional tendon-based techniques with nerve transfers for the restoration of upper limb function in tetraplegia: A prospective case series. Lancet. 2019; 394: 565-575.

34. Ledgard JP, Gschwind CR. Evidence for efficacy of new developments in reconstructive upper limb surgery for tetraplegia. J Hand Surg. 2020; 45: 43-50.

35. Brown JM. Nerve transfers in tetraplegia 1: Background and technique. Surg Neurol Int. 2011; 2: 121.

36. Messina A, Van Zyl N, Weymouth M, Flood S, Nunn A, Cooper C, et al. Morphology of donor and recipient nerves utilized in nerve transfer surgery to restore upper limb function after cervical spinal cord injury. Brain Sci. 2016; 6: 42.

37. Beauparlant J, van den Brand R, Barraud Q, Friedli L, Musienko P, Dietz V, et al. Undirected compensatory plasticity contributes to neuronal dysfunction after severe spinal cord injury. Brain. 2013; 136: 3347-3361.

38. Kaelan C, Jacobsen PF, Kakulas BA. An investigation of possible transynaptic neuronal degeneration in human spinal cord injury. J Neurol Sci. 1988; 86: 231-237.

39. McBride RL, Feringa ER. Ventral horn motoneurons 10, 10 and 53 weeks after T9 spinal cord transection. Brain Res Bull. 1991; 28: 57-60.

40. Wild BM, Mohan R, Morris R. Rat motor neurons caudal to a rubrospinal tract (RST) transection remain viable. Neuroscience. 2017; 364: 157-163.

41. Yokota K, Kubota K, Kobayakawa K, Saito T, Hara M, Kijma K, et al. Pathological changes of distal motor neurons after complete spinal cord injury. Mol Brain. 2019; 12: 4.

42. Thomas CK, Häger CK, Klein, CS. Increases in human motoneuron excitability after cervical spinal cord injury depend on the level of injury. J Neurophysiol. 2017; 117: 684-691

43. Gazula VR, Roberts M, Luzzio C, Jawad AF, Kalb RG. Effects of limb exercise after spinal cord injury on motor neuron dendrite structure. J Comp Neurol. 2004; 476: 130-145. 
44. Pinco $M$, Lev-Tov A. Synaptic excitation of $\alpha$-motoneurons by dorsal root afferents in the neonatal rat spinal cord. J Neurophysiol. 1993; 70: 406-417.

45. O'Hanlon GM, Lowrie MB. The effects of neonatal dorsal root section on the survival and dendritic development of lumbar motoneurons in the rat. Eur J Neurosci. 1996; 8: 1072-1077.

46. Soha JM, Herrup K. Abnormal Purkinje cell dendrites in lurcher chimeric mice result from a deafferentation-induced atrophy. J Neurophysiol. 1996; 29: 330-340.

47. Cope TC, Bodine SC, Fournier M, Edgerton VR. Soleus motor units in chronic spinal transected cats: Physiological and morphological alterations. J Neurophysiol. 1986; 55: 1202-1220.

48. Hounsgaard J, Hultborn $H$, Jespersen B, Kiehn O. Bistability of $\alpha$-motoneurones in the decerebrate cat and in the acute spinal cat after intravenous 5-hydroxytrypophan. J Physiol. 1988; 405: 345-367.

49. Bennett DJ, Li Y, Harvey PJ, Gorassini M. Evidence for plataeau potentials in tail motoneurons of awake chronic spinal rats with spasticity. J Neurophysiol. 2001; 86: 1972-1978.

50. Gorassini M, Bennett DJ, Kiehn O, Eken T, Hultborn H. Activation patterns of hindlimb motor units in the awake rat and their relation to motoneuron intrinsic properties. J Neurophysiol. 1999; 82: 709-717.

51. Cormery B, Beaumont E, Csukly K, Gardiner P. Hindlimb unweighting for 2 weeks alters physiological properties of rat hindlimb motoneurones. J Physiol. 2005; 568: 841-850.

52. Czeh G, Gallego R, Kudo N, Kuno M. Evidence for the maintenance of motoneurone properties by muscle activity. J Physiol. 1978; 281: 239-252.

53. Mayer RF, Burke RE, Toop J, Walmsley B, Hodgson JA. The effect of spinal cord transection on motor units in cat medial gastrocnemius muscles. Muscle Nerve. 1984; 7: 23-31.

54. Jefferson D, Neary D, Eames RA. Renaut body distributiion at sites of human peripheral nerve entrapment. J Neurol Sci. 1981; 49: 19-29.

55. Neary D, Ochoa J, Gilliatt RW. Sub-clinical entrapment neuropathy in man. J Neurol Sci. 1975; 24: 283-298.

56. Hong CC, Thambiah MD, Manohara R. Quadilateral space syndrome: The forgotten differential. J Othop Surg. 2019; 27: 2309499019847145.

57. Frey D, Schneider C, Xu L, Borg J, Spooren W, Caroni P. Early and selective loss of neuromuscular synapse subtypes with low sprouting competence in motoneuron diseases. J Neurosci. 2000; 20: 2534-2542.

58. Schaefer AM, Sanes JR, Lichtman JW. A compensatory subpopulation of motor neurons in a mouse model of amyotrophic lateral sclerosis. J Comp Neurol. 2005; 490: 209-219.

59. Pun S, Sigrist M, Santos AF, Ruegg MA, Sanes JR, Jessell TM, et al. An intrinsic distinction in neuromuscular junction assembly and maintenance in different skeletal muscles. Neuron. 2002; 34: 357-370.

60. Burns AS, Jawaid S, Zhong H, Yoshihara H, Bhagat S, Murray M, et al. Paralysis elicited by spinal cord injury evokes selective disassembly of neuromuscular synapses with and without terminal sprouting in ankle flexors of the adult rat. J Comp Neurol. 2007; 500: 116-133.

61. Tator $\mathrm{CH}$, Koyanagi I. Vascular mechanisms in the pathophysiology of human spinal cord injury. J Neurosurg. 1997; 86: 483-492.

62. Kwon BK, Tetzlaff W, Grauer JN, Beiner J, Vaccaro AR. Pathophysiology and pharmacologic treatment of acute spinal cord injury. Spine J. 2004; 4: 451-464. 
63. Allison DJ, Green LA, Gabriel DA, Roy BD, Inglis JG, Ditor DS. Elevated concentrations of circulating cytokines and correlations with nerve conduction velocity in human peripheral nerves. J Neuroimmunol. 2014; 277; 134-139.

64. Takigawa T, Yasuda H, Kikkawa R, Shigeta Y, Saida T, Kitasato H. Antibodies against GM1 ganglioside affect $\mathrm{K}^{+}$and $\mathrm{Na}^{+}$currents in isolated rat myelinated nerve fibers. Ann Neurol. 1995; 37: 436-442.

65. Allison DJ, Ditor DS. Immune dysfunction and chronic inflammation following spinal cord injury. Spinal Cord. 2015; 53: 14-18.

66. Lacomis D. Neuromuscular disorders in critically ill patients: Review and update. J Clin Neuromusc Dis. 2011; 12: 197-218.

67. Zhou C, Wu L, Ni F, Ji W, Wu J, Zhang H. Critical illness polyneuropathy and myopathy: A systematic review. Neural Regen Res. 2014; 9: 101-110.

68. Corfas G, Velardez MO, Ko CP, Ratner N, Peles E. Mechanisms and roles of axon-Schwann cell interactions. J Neurosci. 2004; 24: 9250-9260.

69. Johnson C, Holmes WR, Brown A, Jung P. Minimizing the caliber of myelinated axons by means of nodal constrictions. J Neurophysiol. 2015; 114: 1874-1884.

70. Arancibia-Cárcamo IL, Ford MC, Cossell L, Ishida K, Tohyama K, Attwell D. Node of Ranvier length as a potential regulator of myelinated axon conduction speed. Elife. 2017; 28: e23329.

71. Lev-Ram V, Ellisman MH. Axonal activation-induced calcium transients in myelinating schwann cells, sources, and mechanisms. J Neurosci. 1995; 15: 2628-2637.

72. Redondo-Castro E, Navarro X. Peripheral nerve alterations after spinal cord injury in the adult rat. Spinal Cord. 2013; 51: 630-633.

73. Lee SM, Sha D, Mohammed AA, Asress S, Glass JD, Chin LS, et al. Motor and sensory neuropathy due to myelin infolding and paranodal damage in a transgenic mouse model of charcot-marietooth disease type 1c. Hum Mol Genet. 2013; 22: 1755-1770.

74. Hahn AF, Ainsworth PJ, Bolton CF, Bilbao JM, Vallat JM. Pathological findings in the x-linked form of Charcot-Marie-Tooth disease: A morphometric and ultrastructural analysis. Acta Neuropathol. 2001; 101: 129-139.

75. Svennigsen AF, Dahlin LB. Repair of the peripheral nerve-remyelination that works. Brain Sci. 2013; 3: 1182-1197.

76. Gutman E, Holubar J. The degeneration of peripheral nerve fibres. J Neurol Neurosurg Psychiatr. 1950; 13: 89-105.

77. Renaud G, Llano-Diez M, Ravara B, Gorza L, Feng HZ, Jin JP, et al. Sparing of muscle mass and function by passive loading in an experimental intensive care unit model. J Physiol. 2013; 591: 1385-1402.

78. Dupont-Versteegden EE, Houlé JD, Dennis RA, Zhang J, Knox M, Wagoner G, et al. Exerciseinduced gene expression in soleus muscle is dependent on time after spinal cord injury in rats. Muscle Nerve. 2004; 29: 73-81.

79. Cote MP, Azzam GA, Lemay MA, Zhukareva V, Houlé JD. Activity-dependent increase in neurotrophic factors is associated with an enhanced modulation of spinal reflexes after spinal cord injury. J Neurotrauma. 2011; 28: 299-309

80. Tam SL, Archibald V, Jassar B, Tyreman N, Gordon T. Increased neuromuscular activity reduces sprouting in partially denervated muscles. J Neurosci. 2001; 21: 654-667. 
81. Angelov DN, Ceynowa M, Guntinas-Lichius O, Streppel M, Grosheva M, Kiryakova Al, et al. Mechanical stimulation of paralyzed vibrissal muscles following facial nerve injury in adult rat promotes full recovery of whisking. Neurobiol Dis. 2007; 26: 229-242.

82. Kalb RG. Regulation of motor neuron dendrite growth by NMDA receptor activation. Development. 1994; 120: 3063-3071.

83. Mizrahi A, Libersat F. Afferent input regulates the formation of distal dendritic branches. J Comp Neurol. 2002; 452: 1-10.

84. Lee M, Kiernan MC, Macefield V, Lee BB, Lin SY. Short-term peripheral nerve stimulation ameliorates axonal dysfunction after spinal cord injury. J Neurophysiol. 2015; 113: 3209-3218.

85. Martin R, Sadowsky C, Obst K, Meyer B, McDonald J. Functional electrical stimulation in spinal cord injury: From theory to practice. Top Spinal Cord Inj Rehabil. 2012; 18: 28-33

86. Marquez-Chin C, Popovic MR. Functional electrical stimulation therapy for restoration of motor function after spinal cord injury and stroke: A review. Biomed Eng OnLine. 2020; 19: 34.

87. Davis GM, Hamzaid NA, Fornusek C. Cardiorespiratory, metabolic, and biomechanical responses during functional electrical stimulation leg exercise: Health and fitness benefits. Artif Organs. 2008; 32: 625-629.

88. Griffin L, Decker MJ, Hwang JY, Wang B, Kitchen K, Ding Z, et al. Functional electrical stimulation cycling improves body composition, metabolic and neural factors in persons with spinal cord injury. J Electromyogr Kinesiol. 2009; 19: 614-622.

89. Nguyen Q, Sanes JR, Lichtman JW. Pre-existing pathways promote precise projection patterns. Nature Neurosci. 2002; 5: 861-867.

90. Hamilton SK, Hinkle ML, Nicolini J, Rambo LN, Rexwinkle AM, Rose SJ, et al. Misdirection of regenerating axons and functional recovery following sciatic nerve injury in rats. J Comp Neurol. 2011; 519: 21-33.

91. Dowsing BJ, Hayes A, Bennett TM, Morrison WA, Messina A. Effects of LIF dose and laminin plus fibronectin on axotomized sciatic nerves. Muscle Nerve. 2000; 23: 1356-1364.

92. English AW. Enhancing axon regeneration in peripheral nerves also increases functionally inappropriate reinnervation of targets. J Comp Neurol. 2005; 490: 427-441.

93. Wang W, Liu W, Zhu H, Li F, Yan W, Shi W, et al. Electrical stimulation promotes BDNF expression in spinal cord neurons through $\mathrm{Ca}^{2+}$ - and erk-dependent signalling pathways. Cell $\mathrm{Mol}$ Neurobiol. 2011; 31: 459-467.

94. Gordon T. Electrical stimulation to enhance axon regeneration after peripheral nerve injuries in animal models and humans. Neurotherapeutics. 2016; 13: 295-310.

95. Al-Majed AA, Neumann CM, Brushart TM, Gordon T. Brief electrical stimulation promotes the speed and accuracy of motor axonal regeneration. J Neurosci. 2000; 20: 2602-2608.

96. Sabatier MJ, Redmon N, Schwartz G, English AW. Treadmill training promotes axon regeneration in injured peripheral nerves. Exp Neurol. 2008; 211: 489-493.

97. Asensio-Pinilla E, Udina E, Jamarillo J, Navarro X. Electrical stimulation combined with exercise increase axonal regeneration after peripheral nerve injury. Exp Neurol. 2009; 219: 258-265.

98. Herbison GJ, Jaweed MM, Ditunno JF. Effect of swimming on reinnervation of rat skeletal muscle. J Neurol Neurosurg Psychiatr. 1974; 37: 1247-1251.

99. Lu MC, Ho CY, Hsu SF, Lee HC, Lin JH, Yao CH, et al. Effects of electrical stimulation at different frequencies on regeneration of transected peripheral nerves. Neurorehabil Neural Repair. 2008; 22: 367-373. 
100.Yeh CC, Lin YC, Tsai FJ, Huang CH, Yao CH, Chen YS. Timing of applying electrical stimulation is an important factor deciding the success rate and maturity of regenerating rat sciatic nerves. Neurorehabil Neural Repair. 2010; 24: 730-735.

101.Zou KJ, Gordon T, Chan KM, Borscel GH. Electrical stimulation to enhance peripheral nerve regeneration: Update in molecular investigations and clinical translation. Exp Neurol. 2020; 332: 113397.

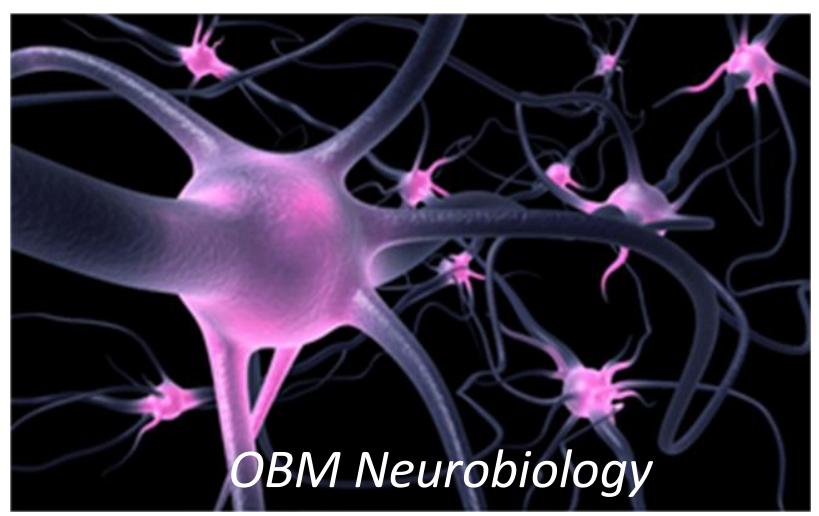

Enjoy OBM Neurobiology by:

1. Submitting a manuscript

2. Joining volunteer reviewer bank

3. Joining Editorial Board

4. Guest editing a special issue

For more details, please visit:

http://www.lidsen.com/journals/neurobiology 